
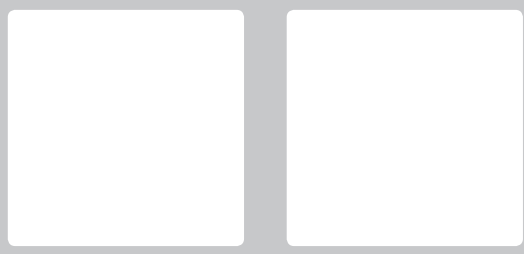

\title{
ADERÊNCIA AOS CRITÉRIOS DE SUSTENTABILIDADE PELOS ÓRGÃOS FEDERAIS NO ESTADO DE SÃO PAULO
}

\section{Adherence to Sustainability Criteria for Federal Organs in the State of São Paulo}

\section{Jose Orcelio do Nascimento}

Doutorando em contabilidade e controladoria. Fundação Álvares

Penteado. São Paulo, SP. Brasil.e-mail:jorcelio@uol.com.br

\section{Edmundo Henrique Brandeburski}

Especialista em controladoria pública. Fundação Álvares Penteado. São Paulo, SP. Brasil.e-mail:edmundohb@gmail.com

\section{Marcus Vinicius Moreira Zittei}

Doutor em ciências contábeis e Administração. Fundação Álvares Penteado. Professor. São Paulo, SP. Brasil. e-mail:marcuszittei@zittei.com.br

\section{Leonardo Fabris Lugoboni}

Doutor e mestre em administração. Fundação Álvares Penteado. Professor. São Paulo, SP. Brasil.e-mail: leo_fabris@hotmail.com

\section{RESUMO}

As políticas de sustentabilidade têm sido cada vez mais reconhecidas como solução para a integração ambiental nos processos de compra que envolvem o setor público. O contrato administrativo para a contratação no setor público apresenta os direitos e deveres de todas as partes envolvidas, pois é um reflexo leal do edital e não agrega qualquer inovação a esse documento convocatório. $\mathrm{O}$ objetivo deste artigo foi analisar a aderência dos órgãos federais às exigências de sustentabilidade em seus processos de compra. A metodologia utilizada contou com análise documental e é de natureza qualitativa. O material analisado compreendeu documentos relativos aos processos licitatórios realizados pelos órgãos federais do Estado de São Paulo, nos últimos cinco anos. Os resultados mostram que houve processos licitatórios que apresentaram requisitos de sustentabilidade e processos de licitação que não apresentaram tais requisitos. Além disso, as constatações tornam evidente que alguns órgãos públicos têm familiaridade com critérios de sustentabilidade, enquanto outros não.

Palavras-chave: Licitação. Sustentabilidade. Aderência.

\section{ABSTRACT}

Sustainability policies have been increasingly recognized a solution to environmental integration in procurement processes that involve the public sector. The Administrative Agreement for contracting in the public sector presents the rights and duties of all parties involved, as it is a loyal reflection of the public notice and it does not add any innovation to this convocation document. The objective of this paper was to analyze the adherence of federal agencies to sustainability requirement $s$ in their procurement processes. The methodology used relied on documental analysis and is of a qualitative nature. The material analyzed comprised documents regarding bidding processes carried out by federal agencies of the State of Sao Paulo in the past five years. Results show that there were both bidding processes that presented sustainability requirements and bidding processes that did not present such sustainability requirements in the past five years. Moreover, findings make it evident that some public agencies have familiarity with sustainability criteria, while others do not.

Keywords: Bidding. Sustainability. Adherence. 


\section{INTRODUÇÃO}

Impulsionados pela reconhecida necessidade de desenvolvimento e implementação de políticas sustentáveis, diversas iniciativas e normativos já vêm culminando na inserção e na obrigação de critérios de sustentabilidade nos instrumentos convocatórios das licitações para contratos públicos.

Segundo Biderman (2008), as licitações sustentáveis são soluções para integrar considerações ambientais e sociais aos estágios do processo de compra e contratação pelos agentes públicos, com a vantagem de que as organizações públicas poderiam usar de seu poder de compra para dar um sinal ao mercado a favor da sustentabilidade.

Conforme Garcia et al. (2012), contemplar critérios ambientais em aquisições públicas é uma tendência já consagrada em outros ordenamentos jurídicos e acolhida por alguns entes federativos.

Para a Advocacia Geral da União (AGU, 2016a), a licitação sustentável não pode mais ser considerada como exceção no cotidiano da Administração Pública. Ao contrário, ainda que sua implantação esteja ocorrendo de maneira gradativa, a realização da licitação sustentável pela Administração Pública deixou de ser medida excepcional para ser a regra geral.

Justen Filho (2012) comenta que o instrumento contratual, resultado posterior à licitação, não gera inovações no tocante às condições estabelecidas para a licitação. Todas as cláusulas contratuais que poderiam influenciar na participação, ou não, de interessados e, ainda, na formulação de propostas, estarão presentes no edital. $O$ contrato administrativo filia-se ao ato que lhe deu origem, ou seja, vincula-se ao instrumento convocatório, do qual os participantes têm pleno acesso, passando a concordar e a ele se vincular no momento da participação na licitação. Entre as condições exigidas, enquadram-se os critérios sustentáveis.

O objetivo geral desta pesquisa foi avaliar a aderência aos critérios de sustentabilidade pelos órgãos federais do Estado de São Paulo e sua evolução, no decorrer dos últimos cinco anos.

Tal abordagem se justifica, de maneira geral, à vista da rotineira observação da existência de vastas legislações e orientações, apesar de, muitas vezes, ocorrer sem a efetiva constatação do resultado, ou seja, do cumprimento dessas normas. Ainda, esta pesquisa se sustenta por acreditar que a busca e exposição de informações correlatas podem exercer papel importante para evidenciar e trazer, à sociedade e aos gestores públicos, o entendimento de que é necessário incentivar a utilização dos critérios sustentáveis e contribuir, efetivamente, para os resultados almejados por esses critérios.

Este estudo visa responder ao seguinte questionamento: Os órgãos federais do Estado de São Paulo vêm aderindo, nos últimos cinco anos, de forma crescente e com previsão das exigências em seus atos convocatórios, aos critérios de sustentabilidade contidos nas licitações?

\section{REFERENCIAL TEÓRICO}

\subsection{CONTRATOS PÚBLICOS}

A licitação é o procedimento administrativo legal previsto para as contratações de compras e serviços realizadas por entidades do governo. No art. 37, inciso XXI, da Constituição Federal encontra-se a base legal da obrigatoriedade da licitação.

\begin{abstract}
Art. 37. A administração pública direta e indireta de qualquer dos Poderes da União, dos Estados, do Distrito Federal e dos Municípios obedecerá aos princípios de legalidade, impessoalidade, moralidade, publicidade e eficiência e, também, ao seguinte:

XXI - ressalvados os casos especificados na legislação, as obras, serviços, compras e alienações serão contratados mediante processo de licitação pública que assegure igualdade de condições a todos os concorrentes, com cláusulas que estabeleçam obrigações de pagamento, mantidas as condições efetivas da proposta, nos termos da lei, o qual somente permitirá exigências de qualificação técnica e econômica, indispensáveis à garantia do cumprimento das obrigações. (BRASIL, 1988)
\end{abstract}

Amparados pela previsão da Carta Magna, diversos normativos sobre o tema estão vigentes no ordenamento jurídico, entre os quais a Lei Geral de Licitações (LGL) é a principal. Esta, em seu art. 37, inciso XXI da Constituição Federal, regulamenta e institui normas para licitações e contratos da Administração Pública.

Art. $2^{\circ}$ - Parágrafo único - [...] considera-se contrato todo e qualquer ajuste entre órgãos ou entidades da Administração Pública e particulares, em que haja um acordo de vontades 
para a formação de vínculo e a estipulação de obrigações recíprocas, seja qual for a denominação utilizada. (BRASIL, 1993)

Vale ressaltar que não se pode confundir contrato administrativo com termo de contrato. O termo de contrato é um escrito completo que contém todas as cláusulas cabíveis de forma detalhada, da qual as partes são signatárias, podendo ser substituído por outros instrumentos, com formas distintas, que igualmente promovam a formalização da contratação, conforme previsão do Art. 62 da Lei de Licitações. Logo, deve-se ter em mente que a existência do contrato administrativo independe do formato adotado para sua formalização (JUSTEN FILHO, 2012).

O contrato administrativo filia-se ao ato que lhe deu origem, ou seja, vincula-se ao instrumento convocatório, do qual os participantes têm pleno acesso, passando a concordar e a ele se vincular no momento da participação na licitação. Assim, todas as obrigações a serem cumpridas pelas partes ficam ali definidas, desde as descrições completas, requisitos técnicos necessários, até os critérios sustentáveis cabíveis e julgados necessários pela administração.

De acordo com Valente (2011), no que se refere à realização de licitações, a Constituição Federal estabelece que exista igualdade de condições a todos os concorrentes e veda a existência de exigências que venham comprometer o caráter isonômico da licitação.

Assim, para que o administrador público realize licitações sustentáveis, torna-se necessário enfrentar o desafio de saber ponderar a aplicabilidade do princípio da isonomia, que orienta os procedimentos licitatórios, e as diretrizes de proteção ambiental e de desenvolvimento sustentável previstas na Constituição, no sentido de garantir o aspecto isonômico dos procedimentos licitatórios.

\subsection{DESENVOLVIMENTO SUSTENTÁVEL}

O ideal de desenvolvimento sustentável remonta à década de 1970, quando a Organização das Nações Unidas (ONU), à época da Conferência de Estocolmo, passou a ocupar-se da reflexão, discussão e disseminação de seus conceitos. Atualmente, o desenvolvimento sustentável já passou a constituir, de forma generalizada, um princípio de direito internacional, culminado na obrigação de sua consideração pelos
Estados que integram a comunidade internacional (AGU, 2016a).

Segundo Valente (2011), vários países passaram a utilizar, como mecanismo do fomento de iniciativas voltadas para a produção de bens e serviços sustentáveis, o poder de compra das entidades governamentais, cujos processos de seletividade de bens e serviços incorporaram critérios de sustentabilidade ambiental.

No Brasil, a tendência também se faz presente. Desde 2010, ano expressivo no país para a inovação dos modelos de compras públicas sustentáveis, diversos normativos e novidades legais vêm direcionando a atuação dos gestores públicos para que adotem as contratações sustentáveis.

\subsubsection{Contratações sustentáveis da Administração Pública}

Segundo a Secretaria do Meio Ambiente do Estado de São Paulo-SMA (2016), as contratações sustentáveis se traduzem em uma forma de inserir critérios ambientais e sociais com o objetivo de maximizar o valor adicionado (utilidade, prazer, satisfação do usuário, satisfação das necessidades, contribuição para operações eficientes) e, concomitantemente, a minimização dos impactos ambientais e sociais adversos.

Alguns discursos contrários às contratações sustentáveis avaliam que exigir critérios dos produtos e serviços almejados pela contratação pode aumentar o custo. Contudo, os gastos pós-aquisição podem transformar uma proposta com valor de compra vantajoso em um grande óbice, já que garantir a manutenção ou o descarte de forma ecológica pode ser caro. Muitos desses requisitos podem ser abordados em um edital de licitação, sem que venham a ferir o princípio da legalidade, ou seja, sem deixar de se enquadrar no que prevê a legislação. Mesmo que o produto ou serviço exija uma quantia inicial mais alta, no decorrer de seu tempo de uso, ele pode se tornar mais barato. Esta medida vem a ser uma das mais apropriadas para a aquisição de produtos sustentáveis (BIDERMAN, 2008).

Por meio das compras públicas, o governo pode ter o poder de promover um enorme estímulo para atividades inovadoras. Na Europa, os contratos públicos têm estado no centro das recentes discussões 
sobre a inovação política a respeito de contratações sustentáveis. (BRAMMER, 2011)

Para Oliveira (2008), ao admitir a discussão sobre contratação sustentável por órgãos públicos, torna-se obrigatória a admissão de questões referentes à sustentabilidade aos critérios de seleção dos contratados, sejam eles fornecedores de bens ou serviços. Assim, a Administração Pública deve definir as condições ou requisitos que contenham exigências sustentáveis necessárias e inseri-las de forma prévia em seus processos, culminando em instrumentos bem preparados, para que, finalmente, sejam firmados os acordos contratuais que contemplem tais critérios.

Victor (2015) recomenda que os governos formulem e implantem uma política de aquisições que reconheça a importância da sustentabilidade e que induza a modelos padrões e de ampla adesão que possam gerar maior consciência de sustentabilidade aos órgãos que realizam compras públicas.

A partir de 2010, o governo brasileiro tem gerado alguns normativos de forma a seguir a tendência mundial. Nesse mesmo ano, foi publicada a Instrução Normativa $\mathrm{n}^{\mathrm{o}}$ 1, pelo Ministério do Planejamento, Orçamento e Gestão, estabelecendo critérios de sustentabilidade ambiental na aquisição de bens, contratação de serviços ou obras na Administração Pública Federal. Esta, talvez, sendo o primeiro normativo que regulou a adoção de critérios de sustentabilidade ambiental no âmbito federal.

Outro fato importante é a criação da Lei $\mathrm{n}^{\mathrm{o}}$ 12.349, em 15 de dezembro de 2010, a qual alterou o art. $3^{\circ}$ da Lei $\mathrm{n}^{\circ} \mathrm{8.666/93}$, introduzindo o desenvolvimento nacional sustentável como uma das finalidades do procedimento licitatório. Segundo a AGU (2016a), essa inovação legislativa tem grande importância para firmar as licitações sustentáveis no Brasil. Facilmente interpretável, evidencia-se como um fundamento jurídico sólido. Ao inserir como objetivo da contratação pública, no art. $3^{\circ}$ da Lei ํㅡㅇㅛ 8.666/93, a promoção do desenvolvimento nacional sustentável, no mesmo patamar normativo das observâncias anteriores, ou seja, do princípio da isonomia e a seleção da proposta mais vantajosa, passou a exigir que a Administração promova o desenvolvimento nacional sustentável como fator de observância logicamente necessário por parte dos gestores públicos nas suas licitações.

\subsection{INICIATIVAS FOMENTADORAS}

Algumas iniciativas públicas para fomentar as aderências aos critérios de sustentabilidade também podem ser observadas. Entre as mais relevantes, citamos a emissão do Guia Nacional de Licitações Sustentáveis da Advocacia Geral da União (AGU), as recomendações contidas nos pareceres jurídicos emitidos pela Consultoria Jurídica da União, subordinada à AGU, e a Comissão Interministerial de Sustentabilidade na Administração Pública (CISAP).

Tais iniciativas evidenciam uma tendência irreversível à ânsia da administração pública federal na adoção de critérios de sustentabilidade já reconhecidamente recomendada pelos normativos vigentes.

\subsubsection{O Guia de Licitações Sustentáveis da AGU}

Nos termos do art. 131 da Constituição Federal, "A Advocacia-Geral da União é a instituição que, diretamente ou através de órgão vinculado, representa a União, judicial e extrajudicialmente, cabendo-lhe, nos termos da lei complementar que dispuser sobre sua organização e funcionamento, as atividades de consultoria e assessoramento jurídico do Poder Executivo".

Entre suas funções institucionais está contida a atuação consultiva, que visa dar segurança jurídica aos atos administrativos praticados pelos dirigentes do Poder Executivo Federal e suas autarquias e fundações públicas, por meio do assessoramento e orientação à viabilização jurídica das licitações (AGU, 2016b).

Em complemento às suas funções, como forma de auxiliar os órgãos na confecção de seus processos licitatórios, a AGU, por meio do Núcleo Especializado em Sustentabilidade, Licitações e Contratos (NESLIC), integrante da estrutura do Departamento de Coordenação e Orientação de Órgãos Jurídicos (DECOR), da Controladoria Geral da União (CGU), emitiu o Guia Nacional de Licitações Sustentáveis, trazendo em seu texto uma coletânea de legislações e normas infralegais que influenciam diretamente na elaboração dos editais, termos de referência e contratos. 
Essa iniciativa visa, ainda, trazer segurança jurídica aos gestores públicos na implementação das licitações sustentáveis, exigência normativa incontestável na atualidade do sistema jurídico nacional (AGU, 2016a).

De maneira organizada e intuitiva, o guia traz, categorizada por objeto, as legislações relacionadas, as principais determinações impostas às providências a serem tomadas e precauções sugeridas aos órgãos contratantes. Textos completos são disponibilizados para inserção direta nos Editais e nos Termos de Referência.

O Guia não é impositivo. Trata-se de material explicativo, de referência, que contém o passo a passo para a elaboração e adoção consciente de critérios de sustentabilidade. Para garantir isso, o texto evidencia três etapas: primeiro, a necessidade da contratação e a possibilidade de reuso/redimensionamento ou aquisição pelo processo de desfazimento; posteriormente, o planejamento da contratação para escolha de bem ou serviço com parâmetros de sustentabilidade; e, por fim, a análise do equilíbrio entre os princípios licitatórios.

\subsubsection{Recomendações dos Pareceres Jurídicos}

Anteriormente à divulgação da licitação, o processo, contendo o edital e seus anexos, deve ser previamente examinado e aprovado por assessoria jurídica da Administração, conforme reza o art. 38 da Lei de Licitações.

Segundo Pereira Junior (2011), essa obrigatoriedade de exame prévio de minutas pela assessoria jurídica tem a finalidade de identificar e apontar defeitos capazes de viciar o procedimento licitatório, evitando sua nulidade e também a do seu resultante contrato. Portanto, é um dever imposto aos gestores públicos, que pode causar consequências no campo das responsabilidades funcionais, em caso de descumprimento ou cumprimento inadequado.

Justen Filho (2012) também comenta sobre a obrigatoriedade da emissão de aprovação prévia por parte de assessoria jurídica, com o fim de evitar a descoberta tardia de defeitos. E incluso nesses defeitos, podemos enquadrar as omissões quanto aos critérios, já que a promoção do desenvolvimento nacional sus- tentável pelas licitações da Administração também é previsão legal contida na lei específica.

Assim, na emissão do parecer jurídico, é verificada a existência de critérios sustentáveis nos instrumentos convocatórios e seus anexos, bem como sua adequabilidade aos objetos pretendidos. Caso se observe a ausência de exigências ambientais naqueles objetos que possuam critérios compatíveis, o parecer tecerá recomendações aos agentes da administração, orientando para que consultem os normativos ou, minimamente, o guia de licitações sustentáveis, solicitando que seus editais sejam corrigidos ou melhorados.

\subsubsection{Comissão Interministerial de Sustentabilidade na Administração Pública}

Criada pelo Decreto ํㅜㄴ.746, de 2012, a Comissão Interministerial de Sustentabilidade na Administração Pública (CISAP) tem natureza consultiva, de caráter permanente. A Cisap possui a finalidade de propor a implementação de critérios, práticas e ações de logística sustentável na Administração Pública Federal direta, autárquica e fundacional e nas empresas estatais dependentes.

Ainda, entre diversas competências, a Cisap tem o papel de propor à Secretaria de Logística e Tecnologia da Informação (SLTI), à qual é vinculada, a criação de critérios e práticas de sustentabilidade nas aquisições, contratações, utilização dos recursos públicos, desfazimento e descarte.

\subsection{PORTAL DE COMPRAS NO GOVERNO FEDERAL}

O Portal de Compras do Governo Federal, instituído pelo Ministério do Planejamento, Orçamento e Gestão, disponibiliza, a qualquer interessado, informações sobre as licitações e contratações realizadas pelas entidades do Governo Federal.

O Portal também permite a realização de processos eletrônicos de aquisição, pois é um módulo do Sistema Integrado de Administração de Serviços Gerais (SIASG), que contempla diversos subsistemas caracterizados por atribuições específicas visando 
à modernização dos processos administrativos dos órgãos públicos federais integrantes (BRASIL, 2016).

Acessando o portal, é possível encontrar os avisos de licitação, as contratações realizadas, a execução de processos de aquisição pela modalidade de pregão, entre outras informações.

\section{METODOLOGIA}

O presente estudo adotou o método de pesquisa exploratória e descritiva já que visa à familiarização com o tema, identificação do contexto, relação e variáveis do assunto, bem como demonstrar qual o comportamento dos órgãos federais do Estado de São Paulo verificado pelos pareceres emitidos pela Advocacia Geral da União.

Conforme Gil (2010), a pesquisa exploratória objetiva criar maior familiaridade com o problema, envolvendo o levantamento bibliográfico, entrevistas e análises de exemplos que estimulem a compreensão do assunto. Segundo esse autor, as pesquisas descritivas têm, primordialmente, a intenção de descrever as características de determinado fenômeno ou, ainda, estabelecer relações entre variáveis. Em complemento, os autores Collado, Lucio e Sampieri (2013) definem que os estudos descritivos servem para analisar como é e como se manifestam um fenômeno e seus componentes.

A pesquisa tem natureza qualitativa. De acordo com Martins e Theóphilo (2009), a pesquisa qualitativa tem como preocupação central descrições, compreensões e interpretações dos fatos ao invés de medições. Martins e Theóphilo (2009) argumentam que a pesquisa qualitativa é usada quando não se dispõe de muitas informações sobre um assunto, ou quando se pretende conhecer o funcionamento de uma estrutura. Dessa forma, não há o objetivo de comprovar evidências pré-estabelecidas; as reflexões sobre o tema surgirão ou se consolidarão durante a coleta e análise de dados.

O campo de pesquisa delimitou-se nas licitações de órgãos públicos federais do Estado de São Paulo que realizaram seus procedimentos por meio de Pregão Eletrônico no Portal de Compras no Governo Federal, Compras Net. As análises se desdobraram, primeiramente, sobre os últimos cinco anos, tendo em vista a recente evolução de determinações legais e de critérios de sustentabilidade, que seriam cada vez menos observados à medida que o espaço de tempo analisado se dilatasse; e, posteriormente, nas licitações de material de consumo que continham o item "pilha alcalina modelo AA", tendo em vista a dificuldade de analisar uma amplitude maior de espaço amostral, caso não fosse adotado outro delimitador.

Utilizou-se o procedimento documental, com pesquisas baseando-se nas legislações vigentes, em publicações disponíveis nos portais governamentais, artigos previamente publicados, livros contendo assuntos correlatos e, principalmente, nos editais das licitações realizadas disponíveis no Compras Net.

A análise documental é apontada por Martins e Theóphilo (2009) como uma das técnicas mais usadas nas pesquisas qualitativas. No entendimento de Gil (2010) a pesquisa documental assemelha-se à pesquisa bibliográfica, diferenciando-se pela natureza das fontes: enquanto na bibliográfica são utilizados trabalhos já desenvolvidos por outros autores a respeito de certo tema, entendam-se, fontes secundárias, na documental são utilizados materiais de fontes mais diversas, tanto aqueles que já receberam algum tipo de análise, quantos aqueles que não receberam nenhum tipo de tratamento analítico.

\section{DISCUSSÃO DOS RESULTADOS}

\subsection{COLETA DE DADOS}

Para que fosse possível a análise, foram efetuadas consultas ao portal eletrônico de compras do governo federal, o Compras Net. Nessas consultas, foram filtradas as licitações realizadas entre $2011 \mathrm{e}$ 2015, de órgãos federais, realizadas pelas unidades sediadas no Estado de São Paulo, na modalidade de Pregão Eletrônico.

Tendo em vista a gigantesca gama de resultados, foi necessária a aplicação de filtros para redução do campo amostral. Assim, a pesquisa ateve-se às licitações de material de consumo que continham, entre seus objetos pretendidos, o item "pilha alcalina tipo AA", dada a sua reconhecida gama de critérios sustentáveis relacionados, conforme é possível observar na consulta ao Guia Nacional de Licitações Sustentáveis. 
Pelo resultado gerado na busca, o sistema não apresenta de forma pronta quais licitações continham critérios sustentáveis, apenas oferece a possibilidade de acesso aos documentos do certame. Assim, tornou-se necessária a leitura individual dos editais, a fim de quantificar quantos deles previam as exigências e quantos não se manifestavam a respeito. Logo, foi analisado, integralmente, cada edital correspondente às licitações apresentadas na busca, extraindo-se, então, o percentual de processos que aderiam aos critérios sustentáveis.

Conforme Valente (2011), no que se refere à realização de licitações, a Constituição Federal esta- belece que exista igualdade de condições a todos os concorrentes e veda a existência de exigências que venham comprometer o caráter isonômico da licitação.

Segundo Oliveira (2008), ao admitir a discussão sobre contratação sustentável a Administração Pública deve definir as condições ou requisitos que contenham exigências sustentáveis necessárias, e inseri-las de forma prévia em seus processos, culminando em instrumentos bem preparados, para que, finalmente, sejam firmados os acordos contratuais que contemplem tais critérios.

Os resultados da pesquisa podem ser observados nas Tabelas nos 1 a 5 :

Tabela 1 Licitações na modalidade Pregão Eletrônico, realizadas em 2011.

\begin{tabular}{|c|c|c|c|}
\hline UNIDADE & № PREGÃO & $\begin{array}{l}\text { EDITAL EXIGE CRITÉRIO } \\
\text { SUSTENTÁVEL }\end{array}$ & $\begin{array}{c}\text { CRITÉRIOS ESPECÍFICOS } \\
\text { PARA PILHAS }\end{array}$ \\
\hline - Hospital Militar de Área de São Paulo & 033/2010 & Não & Não \\
\hline - Academia da Força Aérea & $1001 / 2011$ & Não & Não \\
\hline - MEC-Universidade Federal de São Paulo & $507 / 2010$ & Não & Não \\
\hline - MEC-Universidade Federal de São Paulo & $044 / 2011$ & Não & Não \\
\hline - IV Comando Aéreo Regional & $001 / 2011$ & Não & Não \\
\hline - 2 Batalhão de Engenharia de Combate & $003 / 2011$ & Sim & Sim \\
\hline - Superintendência de Administração do MF & $041 / 2011$ & Não & Não \\
\hline - Inst. Nac. de Colonização e Reforma Agrária & 018/2011 & Não & Não \\
\hline - Prefeitura de Aeronáutica de São Paulo & $017 / 2011$ & Não & Não \\
\hline - Tribunal Regional Eleitoral de São Paulo & 016/2011 & Não & Não \\
\hline - Escola Preparatória de Cadetes do Exército & 014/2011 & Sim & Sim \\
\hline - Fundação Universidade Federal do ABC/SP & $115 / 2011$ & Não & Não \\
\hline - Centro Logístico da Aeronáutica & 038/2011 & Sim & Não \\
\hline - Inst. Fed. de Educ. Cienc. e Tec. de São Paulo & $047 / 2011$ & Não & Não \\
\hline - Centro de Preparação Oficiais Reservas/SP & $006 / 2011$ & Sim & Sim \\
\hline - 370 Batalhão de Infantaria Motorizada & 005/2011 & Não & Não \\
\hline \multicolumn{2}{|l|}{ PERCENTUAL DE ADESÃO } & $25 \%$ & $19 \%$ \\
\hline
\end{tabular}

Fonte: Portal de Compras do Governo Federal - Compras Net. 
Da pesquisa no portal de compras, observa-se que em 2011 poucas licitações previam critérios de sustentabilidade, mesmo de forma genérica. Essa constatação pode se justificar pelo fato de que, naquele ano, o tema ainda estava iniciando suas aparições no ambiente das contratações públicas.

Em 2010, foi publicada a Instrução Normativa no 1 pelo Ministério do Planejamento, Orçamento e Gestão, estabelecendo critérios de sustentabilidade ambiental na aquisição de bens, contratação de serviços ou obras na Administração Pública
Federal, sendo o primeiro normativo que regulou a adoção de critérios de sustentabilidade ambiental no âmbito federal, e em 15 de dezembro de 2010 foi promulgada a Lei $\mathrm{n}^{\circ} \mathrm{0} 12.349$, a qual alterou o art. $3^{\circ}$ da Lei $\mathrm{n}^{-}$8.666/93 introduzindo o desenvolvimento nacional sustentável como uma das finalidades do procedimento licitatório.

Curiosamente, e de forma louvável, a Escola Preparatória de Cadetes do Exército já previu, de forma bastante completa, vários critérios de sustentabilidade, inclusive para os itens de pilha.

Tabela 2 Licitações na modalidade Pregão Eletrônico, realizadas em 2012.

\begin{tabular}{|c|c|c|c|}
\hline UNIDADE & No PREGÃO & $\begin{array}{l}\text { EDITAL EXIGE CRITÉRIO } \\
\text { SUSTENTÁVEL }\end{array}$ & $\begin{array}{l}\text { CRITÉRIOS ESPECÍFICOS } \\
\text { PARA PILHAS }\end{array}$ \\
\hline - Gerência Executiva Santo André/SP & 010/2011 & Não & Não \\
\hline - MEC-Universidade Federal de São Paulo & $040 / 2012$ & Não & Não \\
\hline - MEC-Universidade Federal de São Paulo & $305 / 2012$ & Não & Não \\
\hline - Gerência Executiva Santo André/SP & $008 / 2012$ & Sim & Sim \\
\hline - Prefeitura de Aeronáutica de São Paulo & $019 / 2012$ & Sim & Sim \\
\hline - Parque de Material Aeronáutico de São Paulo & $031 / 2011$ & Sim & Sim \\
\hline - Coord. de Vig. de Portos, Aeroportos e Front./SP & $001 / 2012$ & Não & Não \\
\hline - 12 Grupo de Artilharia de Campanha & $004 / 2011$ & Sim & Não \\
\hline - Escola Preparatória de Cadetes do Exército & $016 / 2012$ & Sim & Sim \\
\hline - Escola de Especialistas de Aeronáutica & $007 / 2012$ & Sim & $\operatorname{Sim}$ \\
\hline - 4 Batalhão de Infantaria Leve & $002 / 2011$ & Sim & Não \\
\hline - Tribunal Regional Eleitoral de São Paulo & $084 / 2012$ & Não & Não \\
\hline - 2 Batalhão de Engenharia de Combate & $007 / 2012$ & $\operatorname{sim}$ & Sim \\
\hline \multicolumn{2}{|l|}{ PERCENTUAL DE ADESÃO } & $62 \%$ & $46 \%$ \\
\hline
\end{tabular}

Fonte: Portal de Compras do Governo Federal - Compras Net.

No ano de 2012, evidencia-se um crescimento das exigências sustentáveis. Mais da metade dos editais já previam, de forma genérica, critérios de sustentabilidade para a seleção de fornecedores aos itens almejados.
A aparição de critérios específicos para a aquisição de pilhas, item escolhido nesta pesquisa para filtragem das licitações, também tiveram mais aparições, sendo alguns deles, mesmo de forma incompleta, já nos moldes do que orienta o Guia Nacional de Licitações Sustentáveis. 
Tabela 3 Licitações na modalidade Pregão Eletrônico, realizadas em 2013.

\begin{tabular}{|c|c|c|c|}
\hline UNIDADE & No PREGÃO & $\begin{array}{l}\text { EDITAL EXIGE CRITÉRIO } \\
\text { SUSTENTÁVEL }\end{array}$ & $\begin{array}{l}\text { CRITÉRIOS ESPECÍFICOS } \\
\text { PARA PILHAS }\end{array}$ \\
\hline - Sup. Regional Receita Federal da 8a RF/SP & 012/2012 & Não & Não \\
\hline - Superintendência de Administração do MF/SP & $072 / 2012$ & Não & Não \\
\hline - MEC-Universidade Federal de São Paulo & $599 / 2012$ & Não & Não \\
\hline - Hospital Militar de Área de São Paulo & $036 / 2012$ & Não & Não \\
\hline - $6^{\circ}$ Circunscrição de Serviço Militar & $002 / 2012$ & Sim & Sim \\
\hline - Gerência Executiva Guarulhos/SP & $005 / 2013$ & Sim & Sim \\
\hline - Gerência Executiva Marília/SP & $005 / 2013$ & Sim & Sim \\
\hline - MEC-Universidade Federal de São Paulo & $355 / 2013$ & Não & Não \\
\hline - Inst. Nac. de Colonização e Reforma Agrária & $022 / 2013$ & Sim & Sim \\
\hline - Indústria de Material Bélico do Brasil/FPV & $044 / 2013$ & Não & Não \\
\hline - Inst. Fed. de Educ., Ciênc. e Tec. de São Paulo & $023 / 2013$ & Sim & Não \\
\hline - Escola de Especialistas de Aeronáutica & $052 / 2013$ & Sim & Sim \\
\hline - Gerência Executiva São Paulo - Leste & $004 / 2013$ & Sim & Sim \\
\hline - 22 Batalhão Logístico & $004 / 2013$ & Sim & Sim \\
\hline - $37^{\circ}$ Batalhão de Infantaria Motorizada & $005 / 2013$ & Sim & Sim \\
\hline \multicolumn{2}{|l|}{ PERCENTUAL DE ADESÃO } & $60 \%$ & $53 \%$ \\
\hline
\end{tabular}

Fonte: Portal de Compras do Governo Federal - Compras Net.

Em 2013, o percentual de adesão aos critérios sofreu pouca variação, podendo-se dizer que não houve evolução em relação ao ano anterior.

Em alguns arquivos, de órgãos assessorados pela AGU, é possível observar a influências dos pareceres jurídicos emitidos por seus advogados. A aparição de textos padronizados já é evidente.

Justen Filho (2012) afirma que a emissão de aprovação prévia por parte de assessoria jurídica destina-se a evitar a descoberta tardia de defeitos. Contido nesses defeitos, podemos enquadrar as omissões quanto aos critérios, já que a promoção do desenvolvimento nacional sustentável pelas licitações da Administração também é previsão legal contida na lei específica.

Mesmo assim, de forma generalizada, a previsibilidade de critérios não é completa, pois algumas sugestões do Guia Nacional de Licitações Sustentáveis, as quais são de fácil adoção pela simples cópia do texto disponibilizado no guia, não são observadas na maioria dos editais analisados.
Nos termos do art. 131 da Constituição Federal, "A Advocacia-Geral da União é a instituição que, diretamente ou através de órgão vinculado, representa a União, judicial e extrajudicialmente, cabendo-lhe, nos termos da lei complementar que dispuser sobre sua organização e funcionamento, as atividades de consultoria e assessoramento jurídico do Poder Executivo".

Entre suas funções institucionais, está contida a atuação consultiva, que visa dar segurança jurídica aos atos administrativos praticados pelos dirigentes do Poder Executivo Federal e de suas autarquias e fundações públicas, por meio do assessoramento e orientação à viabilização jurídica das licitações (AGU, 2016b).

Em complemento às suas funções, como forma de auxiliar os órgãos na confecção de seus processos licitatórios, a AGU emitiu o Guia Nacional de Licitações Sustentáveis trazendo em seu texto uma coletânea de legislações e normas infralegais que influenciam diretamente na elaboração dos editais, 
termos de referência e contratos, pois o Guia não é impositivo.

Neste momento, pode-se dizer que começam os critérios de sustentabilidade começar a ganhar amadurecimento. Assim, era esperado que, como consequência, fosse possível observar um aumento na quantidade de licitações abrangendo critérios sustentáveis em seus editais.

Tabela 4 Licitações na modalidade Pregão Eletrônico, realizadas em 2014.

\begin{tabular}{|c|c|c|c|}
\hline UNIDADE & No PREGÃO & $\begin{array}{l}\text { EDITAL EXIGE CRITÉRIO } \\
\text { SUSTENTÁVEL }\end{array}$ & $\begin{array}{l}\text { CRITÉRIOS ESPECÍFICOS } \\
\text { PARA PILHAS }\end{array}$ \\
\hline - Prefeitura de Aeronáutica de São Paulo & $025 / 2013$ & Sim & Sim \\
\hline - Sup. Regional Receita Federal da $8^{a}$ RF/SP & $005 / 2014$ & Não & Não \\
\hline - Superintendência de Administração do MF/SP & $027 / 2014$ & Não & Não \\
\hline - Escritório de Representações/MRE em SP & $001 / 2014$ & Sim & Sim \\
\hline - Gerência Executiva Marília/SP & $005 / 2014$ & Sim & Sim \\
\hline - Gerência Executiva São José dos Campos/SP & $004 / 2014$ & Sim & Sim \\
\hline - Delegacia da Rec. Federal em Sorocaba/SP & $008 / 2013$ & Não & Não \\
\hline - 130 Regimento de Cavalaria Mecanizado & $013 / 2013$ & Não & Não \\
\hline - Fundação Universidade Federal do ABC/SP & $136 / 2014$ & Não & Não \\
\hline - 130 Regimento de Cavalaria Mecanizado & $011 / 2014$ & Sim & Não \\
\hline - Del. da Capitania dos Portos em São Sebastião & $004 / 2014$ & Não & Não \\
\hline - Superint. de Administração em São Paulo & $014 / 2014$ & Sim & Sim \\
\hline - Fundação Universidade Federal de São Carlos/SP & 095/2014 & Não & Não \\
\hline - Fundação Universidade Federal de São Carlos/SP & $217 / 2014$ & Não & Não \\
\hline \multicolumn{2}{|l|}{ PERCENTUAL DE ADESÃO } & $43 \%$ & $36 \%$ \\
\hline
\end{tabular}

Fonte: Portal de Compras do Governo Federal - Compras Net.

No ano de 2014, a pesquisa resultou em uma ligeira queda de licitações que previam critérios sustentáveis, tanto os genéricos quanto os exclusivos do item de filtragem. Contudo, não é possível afirmar se foi apenas o acaso, ou mesmo relacionar com algum fato ocorrido no ano.

Para 2018, decorrido algum tempo das inovações legislativas e das primeiras versões de iniciativas fomentadoras, como resultado de já existir uma maior disponibilidade sobre o assunto, esperava-se observar um acréscimo nas licitações sustentáveis. Contudo, como se observou, isso não ocorreu.
Interessante notar que há unidades gestoras que apresentaram de forma completa as exigências sustentáveis, tanto genéricas quando do item de pilha, como é o caso da Superintendência de Administração de São Paulo. Vale ressaltar que esta unidade gestora pertence ao mesmo órgão que editou o Guia de Licitações Sustentáveis, a AGU, o que certamente facilitou o acesso ou a familiarização com o assunto. $\mathrm{O}$ fato sugere que outras unidades não estão tendo contato com o Guia de Licitações Sustentáveis ou, simplesmente, não estão absorvendo incentivos para utilizá-la. 
Tabela 5 Licitações na modalidade Pregão Eletrônico, realizadas em 2015.

\begin{tabular}{|c|c|c|c|}
\hline UNIDADE & No PREGÃO & $\begin{array}{l}\text { ALGUM CRITÉRIO } \\
\text { SUSTENTÁVEL }\end{array}$ & $\begin{array}{c}\text { CRITÉRIOS ESPECÍFICOS } \\
\text { PARA PILHAS }\end{array}$ \\
\hline - Gerência Executiva Piracicaba/SP & 010/2014 & Não & Não \\
\hline - Mex/Ar. Guerra/SP & $001 / 2015$ & Sim & Não \\
\hline - - 6a Circunscrição de Serviço Militar & $004 / 2014$ & Sim & Sim \\
\hline - Prefeitura da Aeronáutica de São Paulo & $007 / 2015$ & Sim & Sim \\
\hline - MEC - Universidade Federal de São Paulo & $120 / 2015$ & Sim & Sim \\
\hline - Escritório de Repres. do Minist. da Saúde/SP & 010/2015 & Sim & Sim \\
\hline - Gerência Executiva São Paulo - Norte/SP & 006/2014 & Sim & Sim \\
\hline - Del. Especial das Instituições Financeiras/SP & $004 / 2014$ & Não & Não \\
\hline - Indústria de Material Bélico do Brasil/FPV/ & 088/2015 & Não & Não \\
\hline - Escola de Especialistas de Aeronáutica & $108 / 2014$ & Sim & Sim \\
\hline - 37o Batalhão de Infantaria Motorizada & $007 / 2014$ & $\operatorname{sim}$ & $\operatorname{sim}$ \\
\hline - Indústria de Material Bélico do Brasil/FPV/ & $009 / 2015$ & Não & Não \\
\hline - Centr. Nac. de Monit. e Alert. de Desast. Naturais & 010/2015 & Sim & Sim \\
\hline - Del. da Rec. Fed. de Adm. Tributária em SP & $006 / 2015$ & Não & Não \\
\hline \multicolumn{2}{|l|}{ PERCENTUAL DE ADESÃO } & $64 \%$ & $57 \%$ \\
\hline
\end{tabular}

Fonte: Portal de Compras do Governo Federal - Compras Net.

Finalmente, no último ano de pesquisa, o quantitativo voltou a apresentar percentuais próximos dos anos 2012 e 2013. Manteve-se também, na maioria dos casos, a não abrangência total dos critérios sugeridos pelo Guia de Licitações Sustentáveis. Observam-se textos padronizados, o que sugere o acatamento das orientações dos pareceres jurídicos.

\subsection{ANÁLISE DOS DADOS}

Da análise às tabelas podemos observar que somente na transição do ano de 2011 para o ano de 2012 tivemos a evolução na quantidade de licitações prevendo critérios de sustentabilidade. Provavelmente seja o resultado das implantações normativas recentes que o âmbito federal vivenciou na época.

Já na análise das demais transições, não fica evidente uma evolução ou um acréscimo contínuo das licitações contendo critérios de sustentabilidade. Nos anos de 2012, 2013 e 2015, os percentuais de adesão são muito semelhantes, verificando-se um ligeiro desvio, o menor, apenas em 2014.
É relevante salientar que, para todas as licitações realizadas, independente da adesão aos critérios de sustentabilidade, foi possível observar sucesso na realização dos certames. Em todos os anos, foram observadas licitações com e sem previsão dos critérios, sendo que, em todos os casos, foi possível declarar fornecedores vencedores para os itens constantes do rol de objetos pretendidos.

Outra observação que se faz dos dados obtidos é o fato de que, em todos os anos, houve órgãos que previram algum critério sustentável nos seus editais, mas não aqueles diretamente relacionados ao item de pilha. Tal fato pode se justificar pelo fato de que todos os editais analisados continham diversos materiais de consumo, ou seja, não licitaram somente a aquisição de pilhas. Assim, os gestores optaram por abordar critérios genéricos, negligenciando a previsão específica de critérios relacionados exclusivamente às pilhas.

Observam-se órgãos mais habituados do que outros, com critérios de sustentabilidade nos processos licitatórios; a omissão destes critérios deve ser questionada pelo Controle Externo, o Tribunal de 
Contas da União, lembrando que a Administração Pública Federal é um grande comprador de mercadorias e atitudes que estimulam o desenvolvimento sustentável e possibilitam externalidades positivas que beneficiam toda a sociedade.

Nota-se, ainda, que não existe uma grande variação na quantidade total de licitações contendo o item "pilha alcalina modelo AA", realizado na modalidade Pregão Eletrônico no Compras Net por órgãos federais no âmbito do Estado de São Paulo.

\section{CONSIDERAÇÕES FINAIS}

A adesão aos critérios de sustentabilidade não impediu o sucesso dos certames. Em todos os anos, foram realizadas licitações com e sem previsão dos critérios e, em todos os casos, foi possível declarar fornecedores vencedores para os itens almejados.

Dos resultados, também se constata que apenas de 2011 para 2012 houve uma evolução perceptível na quantidade de licitações prevendo critérios de sustentabilidade. Não ficou evidente, nos demais anos, uma evolução, ou mesmo involução grave, na quantidade de licitações que continham critérios sustentáveis.

Destaca-se, ainda, que alguns órgãos aderem previsões de sustentabilidade de forma genérica, sem atentar-se às exigências específicas dos objetos contidos em seus editais, enquanto outros órgãos contemplam, de forma completa, as sugestões e legislações relacionadas ao assunto. Fica patente a familiaridade e preocupação com o desenvolvimento sustentável de algumas entidades federais em relação a outras.

Conclui-se que, nos últimos cinco anos, os órgãos federais do Estado de São Paulo não estão aderindo, de forma crescente, aos critérios de sustentabilidade, com previsão dessas exigências em seus atos convocatórios.

Para os trabalhos futuros, recomenda-se a ampliação do espaço amostral, observando editais com outros itens de grande relevância sustentável. Outra sugestão a considerar é a pesquisa nos demais estados da federação ou, ainda, a análise dos procedimentos licitatórios de outros países.

Mais relevante ainda, seria avaliar o produto das contratações, ou seja, se os produtos entregues ou serviços realizados cumpriram, efetivamente, os critérios exigidos, na licitação e nas Políticas Públicas, tal como a utilização de licitações sustentáveis, possibilitam um desenvolvimento sustentável no Brasil exigindo que fornecedores de produtos adquiridos pela Administração Pública forneçam produtos conforme as exigências dos processos licitatórios, o que beneficiará toda a sociedade.

\section{REFERÊNCIAS}

AGU-ADVOCACIA-GERAL DA UNIÃO. Consultoria-Geral da União. Guia Nacional de Licitações Sustentáveis / Flávia Gualtieri de Carvalho, Maria Augusta Soares de Oliveira Ferreira e Teresa Villac, Brasília: versão 2016. AGU, 2016a.

Funções Institucionais. Disponível em: <http://agu.gov.br/page/content/detail/id_ conteudo/200643>. Acesso em: 28 out. 2016.

BIDERMAN, R. et al. Guia de compras públicas sustentáveis: uso do poder de compra do governo para a promoção de desenvolvimento sustentável. São Paulo: FGVces, 2008.

BRAMMER, S. et al. Sustainable procurement in the public sector: an international comparative study. International Journal of Operations \& Production Management. v. 31, no 4, p. 452-476, 2011

BRASIL, Constituição da República Federativa do Brasil. 1988. Disponível em: <https://www.planalto. gov.br/ccivil_03/constituicao/constituicao.htm>. Acesso em: 18 out. 2016.

, Decreto $\mathrm{n}^{\mathrm{0}} 7.746$, de 5 de junho de 2012. Regulamenta o art. 3ํ da Lei no 8.666 , de 21 de junho de 1993, para estabelecer critérios, práticas e diretrizes para a promoção do desenvolvimento nacional sustentável nas contratações realizadas pela administração pública federal, e institui a Comissão Interministerial de Sustentabilidade na Administração Pública - CISAP. Disponível em $<$ http://www.planalto.gov.br/ccivil_03/_ato20112014/2012/decreto/ d7746.htm>. Acesso em: 28 out. 2016. 
Instrução Normativa no 01, de 19 de janeiro de 2010. Dispõe sobre os critérios de sustentabilidade ambiental na aquisição de bens, contratação de serviços ou obras pela Administração Pública Federal direta, autárquica e fundacional e dá outras providências. Disponível em: <http://www.comprasnet.gov.br/legislacao/legislacaoDetalhe.asp?ctdCod= 295>. Acesso em: 11 nov. 2016.

. Lei no 8.666, de 21 de junho de 1993. Regulamenta o art. 37, inciso XXI, da Constituição Federal, institui normas para licitações e contratos da administração pública e dá outras providências. Disponível em: <http://www.comprasnet.gov.br/ legislacao/leis/lei8666.pdf>. Acesso em: 27 set. 2016.

. Lei $\mathrm{n}^{\mathrm{0}} 12.349$, de 15 de dezembro de 2010 . Altera as Leis $\mathrm{n}^{\circ}$ 8.666, de 21 de junho de 1993, 8.958, de 20 de dezembro de 1994, e 10.973, de 2 de dezembro de 2004; e revoga o $\$ 1$ o do art. $2^{\circ}$ da Lei no 11.273, de 6 de fevereiro de 2006. Disponível em: <https:// www.planalto.gov.br/ccivil_03/_ato2007-2010/2010/ lei/l12349.htm> Acesso em: 11 nov. 2016.

- COMPRASNET -Portal de Compras do Governo Federal, O que é o compras net. Disponível em: <https://www.comprasnet.gov.br/ajuda/sobre. htm>. Acesso em: 21 nov. 2016.

COLLADO, C. F., LUCIO, P. B.; SAMPIERI, R. H. Metodologia de pesquisa. 5. ed. Porto Alegre: McGraw-Hill, 2013.

CONTRATAÇÕES PÚBLICAS SUSTENTÁVEIS, Portal do Ministério de Planejamento. Disponível em: $<$ http://cpsustentaveis.planejamento.gov.br $>$. Acesso em: 17 ago. 2016.

GARCIA, F. A. et. al. Licitações Públicas Sustentáveis. Revista de Direito Administrativo, Rio de Janeiro, v. 260, p. 231-254, maio/ago. 2012
GIL, A. C. Como elaborar projetos de pesquisa. 5. ed. São Paulo: Atlas, 2010.

JUSTEN FILHO, M. Comentários à lei de licitações e contratos administrativos. 15. ed. São Paulo: Dialética, 2012.

MARTINS, G. A.; THEÓPHILO, C. R. Metodologia da investigação científica para ciências sociais aplicadas. 2 ed. São Paulo: Atlas, 2009.

OLIVEIRA, F. G. Licitações sustentáveis no subsetor de edificações públicas municipais: modelo conceitual. 2008. 328f. Dissertação (Mestrado em Engenharia Civil) - Universidade Federal do Espírito Santo-UFES, Vitória, 2008.

PEREIRA JUNIOR, J. T, et. al. Responsabilidade da assessoria jurídica no processo administrativo das licitações e contratações. Fórum de contratação e gestão pública, 2011.

\section{SECRETARIA DO MEIO AMBIENTE DO ESTADO} DE SÃO PAULO, Licitações sustentáveis. Disponível em: <http://www.ambiente.sp.gov.br/o-que-fazemos-2/licitacoes-sustentaveis/>, Acesso em: 27 set. 2016.

VALENTE, M. A. L. Marco legal das licitações e compras sustentáveis na Administração Pública. Consultoria Legislativa - Câmara dos Deputados de Brasília, 2011.

VICTOR, O. A. Exploring the Impact of Procurement Policies, Lifecycle Analyses and Supplier Relationships on the Integration of Sustainable Procurement in Public Sector. International Journal of Sustainable Energy Development (IJSED), v. 4, p. 179-186, jun. 2015. 